\title{
Investigating cross-linguistic differences in refusal speech act among native Persian and English speakers
}

Ghazanfari, Mohammad

Ferdowsi University of Mashhad, Mashhad, Iran (mghazanfari@um.ac.ir)

Bonyadi, Alireza

Department of English, Urmia Branch, Islamic Azad University,Urmia, Iran (bonyadi.alireza@yahoo.com)

Malekzadeh, Shirin $\triangle$

Department of English Language, Science and Research Branch, Islamic Azad University, Urmia, Iran (sh_malekzadeh196@yahoo.com)

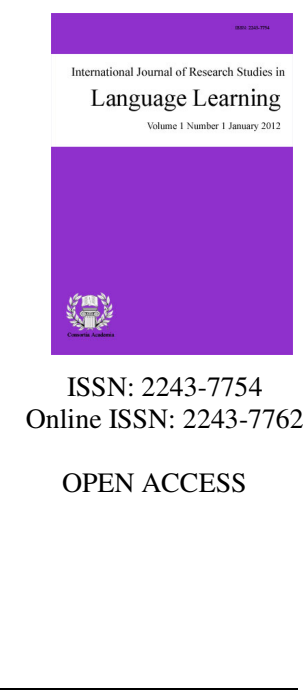

Received: 27 September 2012
Available Online: 17 November 2012

Revised: 19 October 2012

Accepted: 1 November 2012

\section{Abstract}

The aim of this study was to investigate the speech act of refusal performed by native Persian and English speakers with respect to linguistic devices. The study was conducted in two phases. In the first phase, refusal utterances were analyzed with respect to semantic formulas - that is words, phrases, or sentences meeting a particular semantic criterion to perform an act of eliciting. In the second phase, gender differences were examined, as well. One hundred movies (50 in Persian, 50 in English) were used as instruments for gathering the data. The movies were watched closely, and the utterances native speakers employed in their refusals were transcribed and analyzed. Persian speakers used excuse more than English speakers; however, they applied strategies such as regret, non-performative statements, and lack of enthusiasm less frequently than English speakers. The Chi-square $\left(\chi^{2}\right)$ formula was then conducted to find out whether there were any significant differences in performing refusal speech act among the speakers of the two languages. The results showed that there were some differences between the two languages with regard to refusal utterances and gender. Finally, pedagogical implications of study for language learning and teaching have been enumerated.

Keywords: pragmatics; speech act theory; refusal utterances; pragmatic gender differences; movie analysis 


\section{Investigating cross-linguistic differences in refusal speech act among native Persian and English speakers}

\section{Introduction}

\subsection{Pragmatics and Speech Act Theory}

Speaking a language means more than uttering a number of grammatically decent sentences. Individuals can bring change to the environment through their utterances. From a historical point of view, the building blocks for pragmatics as a linguistic discipline were laid by language philosophers and speech-act theorists such as Wittgenstein, Austin, Searle, and Grice (see Nerlich, 2009). In the light of the performative hypothesis, or what he termed as the perlocutionary effect, in the late 1930s, the Oxford philosopher, John L. Austin (as cited in Thomas, 1995) in his lectures was "able to demonstrate that people do not use language just to make statements about the world; they also use language to perform actions, actions which affect or change the world in some way" (p. 44). Put simply, pragmatics is the study of language as it is used in daily communication. In terms of what we are told by Thomas (ibid.), during the 1980s, when it became common for scholars to discuss pragmatics for the first time, they commonly defined the term as 'meaning in use', 'meaning in interaction', or 'the speaker meaning'. Years later, a similar definition was proposed by Yule (1996, p. 127), "the study of intended speaker meaning." In Verschueren's words, pragmatics is "the study of linguistic phenomena from the point of view of their usage properties and processes” (1999, p. 1).

Moreover, the background for the development of pragmatics as a new discipline cannot be traced without considering it in the light of the theory of speech acts. As it was already mentioned, according to Austin, the mere act of speaking is 'doing things with words.' Indeed, for him, "all sentences are speech acts" (Pearson \& Villiers, 2009, p. 207). However, what is important in such a framework is that such acts-for instance, promising or marrying - may only be performed through words. A sentence like 'I now pronounce you husband and wife" "is not a description of an event, but its utterance is the event" (op. cit.). Nevertheless, as Thomas (1995) has emphasized, unless such a declaration is made under certain social conditions, the marriage is not considered legal. Thus, performing different speech acts relies mostly on different situations, conditions of the society and the like. In other words, speech acts are every-day activities like informing, describing, ordering, threatening, complaining, and rejecting, for which we use language.

To put it in a nutshell; "the central tenet of speech act theory is that the uttering of a sentence is, or is part of, an action within the framework of social institutions and conventions. "Saying is (part of) doing, or words are (part of) deeds" (Huang, 2009, p. 1000). In his book; How to Do Things with Words (1962), Austin distinguished between what we say, what we mean, and where we say. To put it in Degand's words (2009, p. 1011) "In addition to providing insight that utterances are used to perform actions, speech act theory assumes that speakers are simultaneously involved in three different speech acts when uttering a sentence":

$>$ a locutionary act: the act of using words to form sentences, ...

$>\quad$ an illocutionary act: the intended action by the speaker, the force or intention behind the words, ...

$>\quad$ a perlocutionary act: the effects that an utterance have on the thoughts, feelings, attitudes, or actions of the hearer

As Searle (1969, p. 16) put it, "The unit of linguistic communication is not, as has generally been supposed, the symbol, word or sentence but rather the production of the symbol or word or sentence in the performance of speech act." When one utters a sentence, does it refer to just words coming to form a sentence? As Austin (1962, 
p. 1) stated, it was hard for philosophers and grammarians to differentiate between questions, commands, and other functions of the language. He also mentioned that beyond each sentence, there is a hidden meaning which may be interpreted differently by interlocutors. He posed the question that: Is saying equal to performing? In other words, by saying getting married, do we mean that two persons are really married? The answer to the above-cited questions are no. The fact is that particular conditions should be considered for each utterance. For example, "for Christian marrying, it is essential that one should not be already married with a wife living, sane, undivorced, and so on" (Austin, 1962, pp. 8-9). It can be concluded that speech act theory revolves around the concept of appropriateness.

The concept of appropriateness is similar to felicity conditions which were originally introduced by Searle (1969). Hudson (2000) stated that well-formed grammatical sentences do not guarantee a proper communication. He further emphasized that some felicity conditions should be taken into consideration in performing speech acts. To make it clearer, for a promise to take place appropriately, the following conditions are needed (Hudson, 2000, p. 321):

\section{Promises X}

$>$ The speaker believes the hearer desires $\mathrm{X}$

$>$ The speaker is able and willing to bring about $\mathrm{X}$

On the basis of the conditions, all sentences cannot have felicity conditions. For example, "I promise you the sun" has not fulfilled the felicity condition in the aforementioned example because the speaker is not able to do his or her promise. In addition, Austin makes a distinction between what he called performatives and what he called constatives (Searle, 1976; Warnock, 1991; Cutting, 2002). The former was not related to truth or falsity but reflects sayings in which doing was accomplished. On the other hand, the latter contained statements, assertions, and the like. Austin believes that speech acts like promising need some conditions to be performed. As it is postulated by Thomas (1995, p. 38), "At a marriage ceremony (in Britain), for example, the words have to be the precise ones laid down." In other words, the precise words have to be utilized.

As argued by Austin (1962), sentences are not just true or false utterances but can be in different forms of questions, exclamations, statements, and expressions of wishes. There are sentences that cannot be reduced to true-false dichotomies. The following examples clarify the point:

$>$ I promise to bring back the book.

$>$ I bet you ten pounds that she won't win.

In the first sentence, the act of promising makes the speaker consider the perlocutionary meaning, which is the influence of the speakers' speech. It means that by promising, we should try to do what we have promised. In the second sentence, the act of betting should be fulfilled in case the speaker will be proved to be wrong. Austin mentioned "whether the sentence works or not" is important. He focused on social conventions rather than the truth of sentences. In addition, Austin proposed three assumptions related to language (as cited in Belza, 2008, p. 24):

$>$ The basic sentence-type in language is declarative (i.e., a statement or assertion)

$>$ The principal use of language is to describe states of affairs (by using statements)

$>$ The meaning of utterances can be described in terms of their truth or falsity.

According to Searle (1975a), speech acts fall into five general classes (cited in Ellis, 2008, p. 160): a) Representatives: These speech acts include assertions relating to true or false values (e.g. asserting, concluding); b) Directives: In these speech acts, the speaker tries to have the hearer do something (e.g. requesting, ordering); c) 
Commissives: Speech acts which result in an obligation to the speaker; that is, they commit the speaker to do something (e.g. promising, threatening); d) Expressives: These speech acts express feelings and attitudes of the speaker (e.g. thanking, congratulating); e) Declarations: Speech acts in which declarative statements are performed (e.g. excommunicating, declaring war, marrying, and firing).

These notions will play a prominent role in shaping the central thoughts for the analysis of refusals in the later parts of the present study. Crucially, the speech act of refusal, the focus of the present study, falls under the category of commissives according to Searle's taxonomy. Moreover, Searle distinguished 'direct' and 'indirect' speech acts. In a direct speech act, there is a relationship between form and function. In direct speech acts, an imperative is used to perform a request. For example, 'pass me the salt'; but in an indirect speech act, the illocutionary force of the speech act is not understood from the surface structure (Intachakra, 2004). For example, an interrogative form of request is 'can you pass me the salt?'

\subsection{Refusal Speech Act}

The speech act of refusal has been one of the important topics in discourse pragmatic research over the past few decades (Fraser, 1990; Wannaruk, 2008). Refusal is one of the speech acts in which communication problems are likely to happen. Refusals are negative responses to requests, invitations, suggestions, offers, and the like which are frequently used in our daily lives (Sadler \& Eroz, 2001). Refusals have been one of the most studied topics in pragmatics and are very important because of their communicative role in everyday social interaction. Generally speaking, how to say "no" is more important than the answer itself. The interlocutors are socially expected to know when to use the appropriate form of refusals in a certain context. Depending on ethnicity and cultural-linguistic values, the speaker must know the appropriate form and its function.

On the whole, refusals are complicated due to the fact that they are influenced by some social factors, namely, age, gender, level of education, social distance, and power (Fraser, 1990; Smith, 1998) and because they require sequences of negotiation. In addition, it is even hard to reject requests, suggestions, and offers in a foreign language due to the fact that misunderstandings may arise if one does not use pragmatic knowledge appropriately. More crucially, refusing others' suggestion, offer and request without hurting their feelings is of great importance since the "inability to say 'no' clearly has led many non-native speakers to offend their interlocutors" (Ramos, 1991, as cited in Al-Kahtani, 2005).

According to Al-Eryani 2008, refusal is not compatible with the listener's expectations, and is often realized through indirect strategies. Searle and Vandervken (1985) defined the speech act of refusal in terms of the negative counterparts to acceptances and consents. Just as one can accept offers, applications, and invitations, so each of these can be refused or rejected. It is worth pointing out that refusals are face-threatening acts (Brown \& Levinson, 1987) and is because they commit the speaker not to perform an action (Searle, 1975b). To summarize, refusals are complex speech acts that require not only long sequences of negotiation and cooperative achievements, but also "face-saving maneuvers to accommodate the noncompliant nature of the act" (Houck \& Gass, 1996, p. 2).

The purpose of this study is to investigate refusal speech acts among Persian and English speakers with regard to semantic formulas - "a word, phrase, or sentence that meets a particular semantic criterion or strategy; any one or more of these can be used to perform the act in question" (Cohen, 1996, p. 265) - used in different types of eliciting tools (request, offer, invitation, or suggestion). Gender differences have also been taken into consideration. Therefore, the study will be conducted in two phases. In the first phase, refusal speech acts of Persian and English speakers will be studied based on movie analyses. In the second phase, gender differences among Persian and English speakers are compared and contrasted. In research studies conducted on refusal speech act, there is scarcity of research done on gender differences. Furthermore, the way the data is elicited in this study is to some extent different from mainstream research on refusal speech act; that is the data for the study were taken from a rather naturalistic context. 
Investigating cross-linguistic differences in refusal speech act among native Persian and English speakers

1.3 Research Questions

1. Are there any significant differences among Persian and English refusal utterances with regard to semantic formulas in different types of eliciting acts?

2. Are there any significant differences among Persian and English refusal utterances in various types of eliciting acts with regard to gender differences?

\section{Review of related literatures}

\subsection{Sequence of refusals}

As Hassani, Dastjerdi, and Mardani (2011, p. 39) mentioned, the usual sequence in refusal strategy application is in three phases:

$>\quad$ Pre-refusal strategies: preparing the addressee for an upcoming refusal;

$>\quad$ Main refusal (Head Act): bearing the main refusal;

$>$ Post-refusal strategies: functioning as emphasizer, mitigator or concluder of the main refusal.

For example, a refusal sequence of someone to his friend's request for going to movies together would be:

Uhm, I'd really like to (pre-refusal), but I can't (main refusal). I'm sorry. I have a

difficult exam tomorrow (post- refusal).

The number of moves in a refusal depends on the type of refusal (that is, whether it is direct or indirect). Compare the following examples:

A: May I go out now? B: No, you may not.

A: Have another cookie. B: Thanks. Everything was so tasty, I couldn't eat another bite.

As it can be seen, there is only one move in the first example of refusal. On the contrary, the person uses more than one move in indirect refusals. Therefore, indirect refusals have more moves to make a refuse.

\subsection{Refusal categorization}

Beebe, Takahashi, and Uliss-Weltz (1990) point out that refusal is a complex speech act which requires a high level of pragmatic competence to be performed successfully. The all-important point is that indirect strategies should be used to eliminate the offense to the hearer. Crucially, interlocutors' awareness of the cross-cultural differences can minimize the possibility of miscommunication. Furthermore, Beebe, Takahashi, and Uliss-Weltz (1990) classify refusals into two main groups: direct refusals and indirect refusals. Direct refusals relate to the fact that the speaker expresses his/her inability to conform using negative propositions including performatives such as "I decline" and non-performatives like "I can't" or "no". Indirect refusals indicate the fact that an offer, an invitation, or a request is indirectly declined. Indirect refusals include different types:

1. Statement of regret: "I'm sorry."

2. Wish: "I wish I could help you."

3. Excuse, reason, explanation: "I have an exam."

4. Statement of alternative. 
Ghazanfari, M., Bonyadi, A., \& Malekzadeh, S.

5. Set condition for future or past acceptance: "If I had enough money, ..."

6. Promise of future acceptance: "I'll do it next time."

7. Statement of principle: "I never drink right after dinner."

8. Statement of philosophy: "One can't be too careful."

9. Attempt to dissuade interlocutor:

9-1. Threat or statement of negative consequences to the requester: "If I knew you would judge me like this, I never did that."

9-2. Criticize the requester: "It's a silly suggestion."

9-3. Guilt trip (waiter to customers who want to sit for a while): "I can't make a living off people who just order tea."

10. Acceptance functioning as a refusal:

10-1. Unspecific or indefinite reply: "I don't know when I can give them to you."

10-2. Lack of enthusiasm: "I'm not interested in diets."

11. Avoidance:

11-1. Non-verbal (silence, hesitation, doing nothing and physical departure)

11-2. Verbal (topic switch, joke, repetition of past request, postponement and hedge);

An example for postponement can be: "I'll think about it."

The above classification is used in current studies on refusal speech act. There are also some adjuncts to the refusals as follows:

12. Statement of positive opinion: "That's a good idea."

13. Statement of empathy: "I know you are in a bad situation."

14. Pause fillers like "well" and "uhm"

15. Gratitude/appreciation: "Thank you."

\subsection{Studies related to refusal speech act}

Investigations into the speech act of refusing have been limited. Some significant studies have been conducted. However, as Brown and Levinson (1987), Fraser (1990), and Smith (1985) argued, from a sociolinguistic perspective, refusals extremely depend upon gender, power, level of education, and social distance. Hence, it can be concluded that refusal speech act is related to various factors which render the task of refusing cumbersome. Beebe, Takahashi, and Uliss-Weltz (1990) conducted a study on Japanese speakers, Japanese English speakers, and American English speakers. They argued that there are great differences between Japanese and Americans in the order, frequently, and content of semantic formulas in refusals. Beebe et al. (1990) found that the Japanese refuses change according to the social status of other interlocutors while Americans are influenced by the degree of familiarity or the social distance from interlocutors. As it is discussed by Beebe et al. (1990), the Japanese did not apologize or regret when they refuse lower status interlocutors. On the other hand, Americans paid attention to social distance. In addition, Japanese gave unspecified excuses, whereas Americans gave specific ones. 
Investigating cross-linguistic differences in refusal speech act among native Persian and English speakers

Robinson (1992) reported that Japanese ESL learners know the differences in appropriate American and Japanese situations of the speech act. Therefore, students with lower proficiency were more influenced by their native language refusal style while students with higher proficiency knew how to complete the DCT items. Chen (1996) used a set of semantic formulas to study refusals employed by American and Chinese speakers of English. According to this view; "direct refusal was not a common strategy for any of the subjects, regardless of their language background" (Chen, 1996, p. 261). In addition, Chen's study revealed that although American speakers used an expression of regret in their refusal speech, Chinese speakers did not employ regret expressions. In another influencing probe, Kwon (2004) studied refusals of 40 Korean speakers in Korea and 37 American English speakers in the USA. The study proved that:

\begin{abstract}
Korean speakers hesitated more frequently and used direct refusal formulas much less frequently than did English speakers. Thus, Korean speakers' refusals at times sounded less transparent and more tentative than those of English speakers. Moreover, Korean speakers frequently paused and apologized before refusing, while English speakers often stated positive opinion and expressed gratitude for a proposed action (p. 339).
\end{abstract}

Moreover, it was also claimed that Korean speakers "tended to take a more mitigating approach dealing with a higher status person as compared to other status types, whereas English speakers did not seem to be particularly sensitive to one status versus another in their refusals across the different situations" (Kwon, 2004, p. 339). Kwon discussed that Korean-as-a-foreign-language learners may fail to convey the illocutionary meaning. Several researchers compared the speech act of refusals across cultural groups and come to the understanding that the features of the refusal strategies used are culture specific. In a study conducted on comparison of refusals among Americans and Chinese; Honglin (2007) concluded that Americans and Chinese employ different ways to express their refusals and the ways varied culture and aspects of the situation. Chinese were more indirect than Americans. In addition, Chinese people were more eager to use politeness strategies and "the Chinese tend to emphasize restoring relationship between people, while Americans emphasize solving the problems in question" (Honglin, 2007, p. 67).

In a similar study, Liao and Bresnahan (1996) compared refusal strategies performed by American and Chinese male and female students. They made a conclusion that both male and female group refused their teacher's refusals easily than their families or friends. In addition, Americans usually refuse with a positive response, followed by a refusal, such as 'I'd love to, but... ', however, Chinese seldom used this strategy. The results also revealed that women used more strategies than men to refuse someone of higher status. Although Liao and Bresnahan (1996) reported that Chinese use less positive opinion than did Americans, other studies showed that Americans are more direct than Germans and Chinese (Beckers, 1999; Chen, 1996). In the same line, Kinjo (1987) made a conclusion that Japanese are more open and direct than Americans.

Another important refusal study was conducted by Morrow (1995) who investigated a research to see the effects of instruction on the using of speech acts. This study revealed that instruction paved the way for the learner to use speech acts of complaints and refusals more native-like. However, King and Silver (1993) on their study on intermediate students concluded that the instruction had little effect on the refusal strategies used by the learners. Furthermore, another study investigated on Taiwanese females and American females on the area of refusal speech act. The results showed that although Taiwanese use more direct refusal, both groups used negative politeness (Widjaja, 1997).

Apart from the aforementioned studies, Ramos (1991) investigated a study that revealed the strategies, rules, and patterns used by Puerto Rican speakers of Spanish to refuse offers, and requests. He also made a comparison between refusals used by speakers of Spanish with native speakers of American English. The results made it clear that Puerto Rican speakers with low proficiency in English refuse in a shorter and simpler way than native speakers of American English. Another study is the refusal research conducted by Tickle (1991). He focused on Japanese speakers transferring pragmatic in English language refusals. The results showed that there is a 
Ghazanfari, M., Bonyadi, A., \& Malekzadeh, S.

difference between direct and indirect refusal speech acts with regard to social power and social relationship.

\section{Method}

\subsection{Design of the study}

The classification of the data into semantic formulas was performed by the researcher. This study was done on three basic parts. Basically, for the first phase, the frequency of refusal utterances were calculated in Persian and English movies based on the classification designed by Beebe et al. (1990). Therefore, the first phase of this study includes the investigation of refusal utterances among native Persian speakers (NPS) and native English speakers (NES). This phase of the study provides the answer for the first question of the study. The second phase of the article deals with gender differences among NPS and NES. The frequency of refusal utterances was calculated to reveal the differences among male and female speakers. This phase answers the second question of the article.

\subsection{Corpus}

In the present study there were no participants and the data were gathered through investigating Persian and English movies. In order to compare Persian and English speech act of refusal, a number of Iranian and English movies were carefully observed to gather refusal messages. Movies are claimed to have important values in speech act studies (Kasper \& Dahl, 1991) because they provide researchers with authentic data - the speakers perform speech acts in real communication contexts. To make the comparison easier and more similar, both Persian and English refusals were collected by analyzing movies ( $\mathrm{N}=100,50$ in Persian and 50 in English). The aim of observing movies was to study the way native speakers in Persian and English languages refuse certain offers in real situations. The criterion for the selection of movies was simply for movies to contain dialogues in which some refusal speech act is performed. The coding was provided for gender differences while transcribing the refusal utterances. The aim of coding gender differences was to investigate the way male and female speakers perform refusals.

\subsection{Instruments}

The main tool for gathering data was through the analysis of dialogues in movies. To compare the Persian and English speech act of refusal, Iranian and English movies were used to gather refusal messages. The refusal speech acts were collected by watching the dialogues of movies ( $\mathrm{N}=100,50$ in Persian and 50 in English). The aim of observing movies was to study the way native speakers in Persian and English cultures refuse certain requests in real contexts.

\section{Results}

\subsection{Refusal formulas}

This paper aimed to probe the issue of refusal speech act among native Persian speakers (NPS) and native English speakers (NES) gathered through naturalistic procedures, exploring the frequency and content of semantic formulas with regard to speakers' gender, types of eliciting acts (requests, invitations, offers, and suggestions), and significance of distribution applying Chi-square. Persian and English speakers used different types of eliciting acts. Among them, request $(\mathrm{n}=315)$ was the most utilized elicitation tool and suggestion $(\mathrm{n}=$ 170) was the least used one. The total sentences transcribed in both languages were 846 eliciting linguistic tools in which the main semantic content was refusal of a request, suggestion, offer, or invitation.

Most of the refusals in Persian and English languages belong to the request eliciting tools, while the least 
number of eliciting utterances are related to suggestion. In the data related to Persian speakers, refusal of suggestions has the minimum frequency, whereas among the English speakers' refusals, offer is the least eliciting tool. The findings are classified according to each eliciting act. Refusals by native speakers of Persian and native speakers of English are compared in terms of the frequency of refusal strategies used in each situation.

Table 1

The Results of chi-square applied to refusals by Persian and English speakers

\begin{tabular}{lccccc}
\hline \multicolumn{1}{c}{ Formulas } & Persian & English & Expected & Sig. & $\chi^{2}$ \\
\hline Performative verbs & 16 & 30 & 23 & .039 & 4.261 \\
Non-performative statements & 28 & 39 & 33.5 & .179 & 1.806 \\
Regret & 26 & 42 & 34 & .052 & 3.765 \\
Wish & 8 & 19 & 13.5 & .034 & 4.481 \\
Excuse, reason, and explanation & 45 & 43 & 44 & .831 & .045 \\
Alternative & 6 & 12 & 9 & .157 & 2 \\
Set condition & 13 & 12 & 12.5 & .841 & .040 \\
Promise of acceptance & 8 & 12 & 10 & .371 & .8 \\
St. principle & 13 & 9 & 11 & .397 & .727 \\
Threat or St. consequence & 10 & 14 & 12 & .414 & .667 \\
Guilt trip & 5 & 5 & 5 & 1 & .000 \\
Criticism & 16 & 16 & 16 & 1 & .000 \\
Request & 27 & 3 & 15 & .000 & 19.2 \\
Off the hook & 16 & 15 & 15.5 & .857 & .032 \\
Self-defense & 15 & 25 & 20 & .114 & 2.5 \\
Unspecific reply & 40 & 25 & 32 & .063 & 3.462 \\
Lack of enthusiasm & 27 & 35 & 31 & .310 & 1.032 \\
Non-verbal avoidance & 21 & 11 & 16 & .077 & 3.125 \\
Topic switch & 17 & 13 & 15 & .465 & .533 \\
Joke & 14 & 7 & 10.5 & .122 & 2.333 \\
Repetition & 6 & 8 & 27 & .276 & 1.185 \\
Postponement & 31 & 23 & 7 & .593 & .286 \\
Hedge & 14 & 6 & 10 & .074 & 3.2 \\
\hline
\end{tabular}

Table 1 reveals that there is a significant difference between Persian and English speakers with regard to performative verbs (.039), wish (.034), and request (.000).

\subsection{Gender differences in refusal speech act}

Considering the refusal utterances, Persian male speakers applied most of the refusals in the data $(\mathrm{N}=239$, out of 846). English male speakers were the second group that performed most of the refusals (221 out of 846). English and Persian female speakers were the third and the fourth group which used refusals with regard to frequency of refusal speech act $(\mathrm{N}=202$ and 184). The results of the Chi-square showed that there is a significant difference just in four semantic formulas: non-performative statements $\left(\chi^{2}=5.388\right.$, sig. $\left.=.020, p<.05\right)$, statements of principle $\left(\chi^{2}=11.636\right.$, sig. $\left.=.001, \mathrm{p}<.05\right)$, self-defense $\left(\chi^{2}=4.9\right.$, sig. $\left.=.027, \mathrm{p}<.05\right)$, and lack of enthusiasm $\left(\chi^{2}=9.290\right.$, sig. $\left.=.002, \mathrm{p}<.05\right)$. Male NPS were more inclined to use formulas related to unspecific reply $(\mathrm{N}=23)$ and excuse $(\mathrm{N}=23)$.

The least used strategy is guilt trip ( $\mathrm{N}=0$ ). Female NPS used excuse, reason, and explanation more than other semantic formulas $(\mathrm{N}=22)$. Alternative sentences and statements of principle are used with the least frequency observed $(\mathrm{N}=1)$. Male NES were more inclined to use non-performative statements $(\mathrm{N}=26)$. Among the semantic formulas, male NES were less inclined to use request $(\mathrm{N}=1)$. Female NES used formulas related to excuse, reason, and explanation more than other observed formulas $(\mathrm{N}=25)$. Among female NES, there is less tendency toward using guilt trip $(\mathrm{N}=0)$. 


\section{Table 2}

Gender differences among Persian and English speakers with regard to refusal utterances

\begin{tabular}{lccccc}
\hline \multirow{2}{*}{ Formulas } & \multicolumn{2}{c}{ Persian } & \multicolumn{2}{c}{ English } & \multirow{2}{*}{ Total } \\
\hline Performative verbs & Male & Female & Male & Female & \\
Non-performative statements & 6 & 10 & 15 & 15 & 46 \\
Regret & 17 & 11 & 26 & 13 & 67 \\
Wish & 11 & 15 & 16 & 24 & 68 \\
Excuse, reason, and explanation & 6 & 2 & 12 & 7 & 27 \\
Alternative & 23 & 22 & 18 & 25 & 88 \\
Set condition & 5 & 1 & 5 & 7 & 18 \\
Promise of acceptance & 10 & 3 & 3 & 9 & 25 \\
St. principle & 3 & 5 & 8 & 4 & 20 \\
Threat or St. consequence & 12 & 1 & 7 & 2 & 22 \\
Guilt trip & 7 & 3 & 7 & 7 & 24 \\
Criticism & 0 & 5 & 5 & 0 & 10 \\
Request & 9 & 7 & 11 & 5 & 32 \\
Off the hook & 9 & 18 & 1 & 2 & 30 \\
Self-defense & 6 & 10 & 6 & 9 & 31 \\
Unspecific reply & 10 & 5 & 17 & 8 & 40 \\
Lack of enthusiasm & 23 & 17 & 9 & 16 & 65 \\
Non-verbal avoidance & 19 & 8 & 24 & 11 & 62 \\
Topic switch & 11 & 10 & 5 & 5 & 31 \\
Joke & 10 & 7 & 4 & 8 & 30 \\
Repetition & 11 & 3 & 5 & 2 & 21 \\
Postponement & 5 & 1 & 2 & 6 & 14 \\
Hedge & 22 & 10 & 12 & 11 & 55 \\
& 4 & 10 & 2 & 4 & 20 \\
\hline & 239 & 184 & 221 & 202 & 846 \\
\hline
\end{tabular}

\section{Conclusion}

\subsection{Elaboration on refusal strategies}

The results of this study shed light on some interesting socio-cultural differences among NPS and NES. The reason for pragmatically different verbal behaviors can be traced back to culture, as the saying goes, "all human behavior is cultural to some extent" (Berry, Poortina, Segall, \& Dasen, 2002, p. 53), since human beings are of sociable nature (Hoorens \& Poortinga, 2000). According to the refusal results, it is concluded that most Persian speakers used refusals as a way to reflect their conformity. The evidence of Persian inclination to establish conformity is that Iranians used less strategies such as regret and self-defense in which the pronoun 'I' is of key importance. Sentences such as 'I'm sorry' and 'it is not my fault' are used more in English movies. The results seem to be in harmony with what has been suggested by Bond and Smith (1996) that conformity is higher in societies that stick to values of conservatism, collectivism, and a preference for status ascription, while it is lower in societies that respect autonomy, individualism, and status achievement (as cited in Berry, Poortinga, Segall, \& Dasen, 2002, p. 59).

The results of the first phase of the study showed that Iranians were more eager to consider themselves as a community when they refused others. In other words, in refusal utterances, they tended to use the word we more than $I$ to keep their conformity even in refusing or rejecting others' requests. Therefore, Persian speakers tend to be of a collectivist nature, valuing group desires, while English speakers used more sentences containing 'I' in refusing utterances (regret and self-defense). Thus, it seems that they value individualistic views. English speakers define 'self' as an individualistic phenomenon rather than a collectivist one. 
The examples are:

Persian: Na, MA bayad hava-ye hamo dashteh bashim. (No, WE should support each other.)

English: No, I'll see you later.

In a similar way, Triandis (2001) proposed other characteristics containing interdependence, sociability, and integrity (for collectivism), and self-reliance, emotional distance from in-groups, and competition (for individualism). In the same vein, other research findings also supported this point. Smith, Dugan, and Trompenaars (1996) mentioned a dimension related to individual's involvement. They made a distinction between loyal involvement (collectivist societies) and utilitarian involvement (individualistic involvement). The former relates to Persian speakers' communication, while the latter deals with English speaking countries.

The findings of Table 1 showed that emotional distance among English speakers is more than Persian speakers and they utilized more formulas related to lack of enthusiasm than the Iranians. The frequency of lack of enthusiasm formula in English was 35, while in Persian it was 27. The examples in two languages are:

Persian: baram mohem nist. (It is not important for me.)

English: It is not worthy of mention.

According to Table 1, another point which can be seen in refusal utterances is that because Iranians show their strong belief in God and utilize God-related expressions, they set a condition to refuse the interlocutors' requests. The examples of setting a condition are phrases such as 'ensha aellah' or 'agar xoda bexahad' (God willing). On the basis of setting a condition, Iranians revealed that apart from their own reasons for refusing a request, such as expression of unwillingness, excuse, lack of enthusiasm, to name a few, other factors may have an influence on refusing the interlocutors' request, such as God-related reasons. To make it clearer, Iranian speakers would like to use 'ensha allah' or 'agar xoda bexahaed' to refuse the request to show their reliance on God and say that for doing everything God has a crucial role. Therefore, Iranian speakers used set condition formulas more than English speakers, suggesting that they are likely to be more traditional in their verbal behavior than the English speakers.

Moreover, according to Table 1, Persian speakers utilized hedge, postponement, non-verbal avoidance, excuse, and unspecific reply more than English speakers. As an example, Persian speakers make a refuse by postponing an invitation, offer, or suggestion to a later time. The frequency of postponement formula in Persian speakers is more than English people. Apparently, they may postpone for some reasons. Firstly, they may be busy and prefer to change the time of action or they need more opportunity to think and arrange their time. Furthermore, they may be unwilling to accept the request. Considering the most eight dominant refusal strategies among Persian and English speakers, Figure 1 can come in handy:

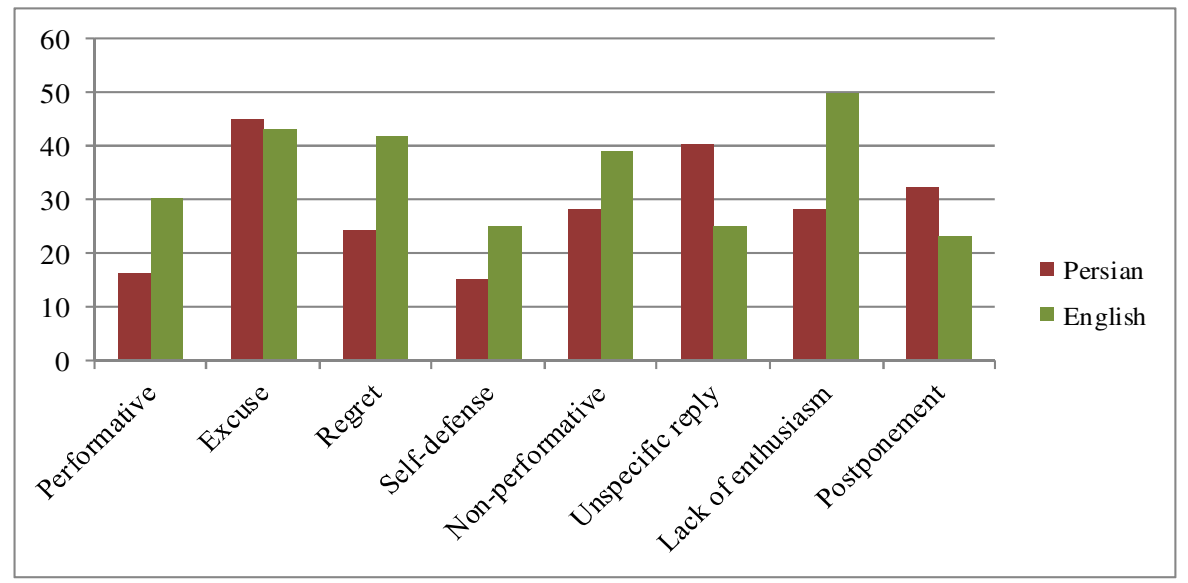

Figure 1. Eight dominant refusal strategies among Persian and English speakers 
Therefore, as to proposing a general understanding of the differences between Persian and English speakers with regard to refusal strategies, it can be mentioned that Persian speakers use excuse, unspecific reply, and postponement more than English speakers. Moreover, Persian speakers use strategies such as regret, non-performative statements, and lack of enthusiasm less than the English speakers.

Pelto (1968) places societies on a continuum of 'tight-loose'. He believes that English speakers come from loose societies. It means that there is less pressure and less role obligation in English speaking societies. However, Persian societies are at the tight end of the continuum. In other words, in tight societies, there is a high level of role obligation to do one's roles. For example, if a person does not accept the interlocutor's offer, suggestion, or invitation, he/she is considered as being rude while in English societies it is not the case. Such an orientation may be observed in the results. English speakers are more direct, more open in their interactions, and more straightforward, using performative verbs and non-performative statements more than Persian speakers. The examples are:

\section{Non-performative verbs:}

$>\quad$ Persian: man nemitoonam biyam. (I can’t come.)

$>$ English: No, No. He is expecting me.

\section{Performative verbs:}

$>$ Persian: majbooram khooneh bemoonam. (I have to stay at home.)

$>$ English: I have to decline your request.

\subsection{Elaboration on gender differences}

The second phase of this study investigated gender differences in refusal utterances. As Berry, Poortinga, Segall, and Dasen (2002) mentioned, the term gender refers to the behaviors or patterns in which a society considers them as appropriate characteristics from men and women. In addition, even men and women's roles are related to the way they behave, take part, and produce utterances in society.

\subsubsection{Gender differences in refusal utterances}

As Table 2 indicates, women used performative verbs, regret, excuse, and unspecific reply with more observed frequencies than men and this shows that females are more inclined to express their feelings than men and are more extrovert. The example is:

$>\quad$ Female: man majboorcem darxasteton ro rad konam. (I have to reject your request.)

> Male: man nemitoonam biyam. (I can't come.)

Moreover, the table shows that females are more likely to be sensitive. Therefore, females express more statements of regret in refusing their conversational partners, as it has been suggested by William and Best's checklist (1982). The frequency of regret formula used by females was 39 , while for males it was 27 . The difference between females and males in regretting is just in the number of frequencies. The examples of regret are:

$>$ Female: I'm sorry that I don't have enough money to lend you.

$>$ Male: I'm really sorry.

According to Table 2, in refusal utterances, men utilized non-performative statements, self-defense, and postponement formula more than women. Apparently, males used non-performatives such as 'negative 
Investigating cross-linguistic differences in refusal speech act among native Persian and English speakers

willingness' and 'no' due to the fact that males tend to be courageous and self-confident in showing their strong opinion. Moreover, males were more indifferent in what sort of effect their reaction might have on the interlocutor while refusing. Therefore, they consider it easier to express their negative willingness. On the contrary, females found it difficult to express their unwillingness because they are shy, and empathetic. The example of non-performatives is:

$>$ Male: No, I don't want to.

$>\quad$ Female: I can't lend you my dress.

As it can be seen in the following schema that excuse was the most used formula by females $(\mathrm{N}=47)$, and non-performative was the most used one by Males $(\mathrm{N}=43)$.

$>$ Females: Excuse $>$ Regret $>$ Unspecific Reply $>$ Performative Verb

$>$ Males: Non-Performative $>$ Lack of Enthusiasm $>$ Postponement $>$ Self-defense

\subsection{Implications of the study}

The implications of this study may be viewed from four perspectives. First, the findings of the study can be of interest to EFL learners, in that they will get familiar with the way native speakers refuse requests in different situations, and they can increase the quality of their interactions by learning how to use certain speech acts properly. Second, teachers can benefit from the findings of this study to teach their learners how to use the refusal speech act. Teachers can design some activities to target pragmatic norms of Persian and English, explaining in which areas Persian and English speakers are similar and in which areas they are at variance. Third, researchers can use the results of this study to compare naturalistic data like these and those provided by, say, DCTs or other elicitation tools. Furthermore, through comparing the results of this study with other similar studies, it is possible to figure out whether there is a universal pattern in performing the refusal speech act. Finally, the findings of the study might be fruitful for material developers to design new textbooks and other educational materials with exercises and activities rightly addressing the pragmatic competence of text users.

\section{References:}

Al-Kahtani, S. W. (2005). Refusals realizations in three different cultures: A speech act theoretically-based cross-cultural study. Journal of King Saud University, 18, 35-57.

Al-Eryani, A. (2008). Refusal strategies by Yemeni EFL learners. The Iranian EFL Journal, 1, 84-101.

Austin, J. L. (1962). How to do things with words. Oxford: Oxford University Press.

Berry, J. W., Poortinga, Y. H., Segall, M. H., \& Dasen, P. R. (2002). Cross-cultural psychology: Research and applications. Cambridge: Cambridge University Press.

Beckers, A. (1999). How to say "no" without saying "no": A study of the refusal strategies of Americans and Germans. Unpublished Doctoral dissertation, The University of Mississippi.

Beebe, L. M., Takahashi, T., \& Uliss-Weltz, R. (1990). Pragmatics transfer in ESL refusals. In R. Scarcella, E. Anderson \& S. D. Krashen (Eds.), On the development of communicative competence in a second language (pp. 55-73). Cambridge, MA: Newbury House Publisher.

Belza, A. (2008). A questionnaire-based comparative study of Irish English and Polish speech act of requesting. Unpublished Doctoral dissertation, Faculty of Philosophy of Silesia, Katowice.

Bond, R., \& Smith, P. B. (1996). Culture and conformity: A meta-analysis of studies using Asch's line judgment task. Psychological Bulletin, 119, 111-137. http://dx.doi.org/10.1037/0033-2909.119.1.111

Brown, P., \& Levinson, S. (1987). Politeness: Some universals in language usage. Cambridge, MA: Cambridge University Press.

Chen, H. (1996). Cross-cultural comparison of English and Chinese metapragmatics in refusals. Unpublished Doctoral dissertation, Indiana University. 
Ghazanfari, M., Bonyadi, A., \& Malekzadeh, S.

Cohen, A. D. (1996). Developing the ability to perform speech acts. Studies of Second Language Acquisition, 18, 253-267. http://dx.doi.org/10.1017/S027226310001490X

Cutting, J. (2002). Pragmatics and discourse: A resource book for students. London and New York. Routledge.

Degand, L. (2009). Speech acts and grammar. In J. L. Mey (Ed.), Concise encyclopedia of pragmatics (2nd ed., pp. 1009-1015). Oxford: Elsevier.

Ellis, R. (2008). The study of second language acquisition. Oxford: Oxford University Press.

Fraser, B. (1990). Perspectives on politeness. Journal of Pragmatics, 14(2), 219-236. http://dx.doi.org/10.1016/0378-2166(90)90081-N

Houck, N., \& Gass, S. M. (1996). Non-native refusals: A methodological perspective. In Gass, S., \& Neu, J. (Ed.), Speech acts across cultures: Challenges to communication in a second language (pp. 45-64). New York: Mouton de Gruyter.

Hudson, G. (2000). Essential introductory linguistics. Massachusetts: Blackwell Publishers Inc.

Hassani, R., Mardani, M., \& Dastjerdi, H. (2011). A comparative study of refusals: Gender distinction and social status in focus. The International Journal of Language Society and Culture, 32, 37-46.

Honglin, L. (2007). A comparative study of refusal speech acts in Chinese and American English. Canadian Social Science, 3(4), 64-67.

Hofstede, G. (1980). Culture's consequences: International differences in work related values. Beverly Hills, CA: Sage.

Hoorens, V., \& Poortinga, Y. (2000). Behavior in social context. In K. Pawlik \& M. Rosenzweig (Eds.), International handbook of psychology (pp. 40-63). London: Sage. http://dx.doi.org/10.4135/9781848608399.n3

Huang, Y. (2009). Speech acts. In J. L. Mey (Ed.), Concise encyclopedia of pragmatics (2nd ed., pp. 1000-1009). Oxford: Elsevier.

Intachakra, S. (2004). Contrastive Pragmatics and Language Learning: Apologies and Thanks in English and Thai. Regional Language Centre Journal, 35, 37-62.

Kasper, G., \& Dahl, M. (1991). Research methods in interlanguage pragmatics. Studies in Second Language Acquisition, 13, 215-247. http://dx.doi.org/10.1017/S0272263100009955

King, K. A., \& Silver, R. E. (1993). Effects of instruction on NNS refusal strategies. Penn Working Papers in Educational Linguistics, 9(1), 47-82.

Kinjo, H. (1987). Oral refusals of invitations and requests in English and Japanese. Journal of Asian Culture, 1 , 83-106.

Kwon, J. (2004). Expressing refusals in Korean and in American English. Multilingua, 23, 339-364. http://dx.doi.org/10.1515/mult.2004.23.4.339

Liao, C., \& Bresnahan, M. (1996). A contrastive pragmatic study on American English and Mandarin refusal strategies. Language Sciences, 18, 703-727. http://dx.doi.org/10.1016/S0388-0001(96)00043-5

Morrow, C. K. (1995). The pragmatic effects of instruction on ESL learners' production of complaint and refusal speech acts. Unpublished Doctoral dissertation, University of New York at Buffalo, Amherst, NY.

Nerlich, B. (2009). History of pragmatics. In J. L. Mey (Ed.), Concise encyclopedia of pragmatics (2nd ed., pp. 328-335). Oxford: Elsevier.

Pearson, P. \& de Villiers, B. (2009). Discourse, narrative and pragmatic development. In J. L. Mey (Ed.), Concise encyclopedia of pragmatics (2nd ed., pp. 206-214). Oxford: Elsevier.

Pelto, P. J. (1968). The difference between tight and loose societies. Transaction, April, 37-40.

Ramos, J. (1991). Pragmatic transfer in refusals among Puerto Rican teenagers speaking English. Unpublished Doctoral dissertation, Teachers College, Columbia University.

Robinson, M. S. (1992). Introspective methodology in interlanguage pragmatics research. In G. Kasper (Ed.), Pragmatics of Japanese as native and target language: Second language teaching and curriculum center (pp. 27-82). University of Hawaii at Manoa.

Sadler, R. W., \& Eroz, B. (2001). "I refuse you!" An examination of English refusals by native speakers of English, Lao, and Turkish. Arizona Working Papers in SLAT, 9, 53-80.

Searle, J. R. (1969). Speech acts: An essay in the philosophy of language. Cambridge: Cambridge University 
Press. http://dx.doi.org/10.1017/CBO9781139173438

Searle, J. R. (1975a). What is speech act? In philosophy in America. Ithaca, NY: Cornell University Press.

Searle, J. R. (1975b). Indirect speech acts. In P. Cole \& J. L. Morgan (Eds.), Syntax and semantics: Vol. 3. Speech acts (pp. 59-82). New York, San Francisco, London: Academic Press.

Searle, J. R. (1976). A classification of illocutionary acts. Language in Society, 5(1), 1-23. http://dx.doi.org/10.1017/S0047404500006837

Searle, J. R. (1979). Expression and meaning. Cambridge: Cambridge University Press. http://dx.doi.org/10.1017/CBO9780511609213

Searle, J., \& Vandervken, D. (1985). Foundations of illocutionary logic. Cambridge: Cambridge University Press.

Smith, C. (1998). Can adults "Just say no?" How gender, status and social goals affect refusals. Unpublished Doctoral dissertation, University of South Florida. http://dx.doi.org/10.1177/0022022196272006

Smith, P. B., Dugan, S., \& Trompenaars, F. (1996). National culture and the values of organizational employees. Journal of Cross-Cultural Psychology, 27, 231-64.

Thomas, J. (1995). Meaning in interaction: An introduction to pragmatics. London: Longman.

Tickle, A. L. (1991). Japanese refusals in a business setting. Papers in Applied Linguistics, 6(2), 84-108.

Triandis, H. C. (2001). Individualism-collectivism and personality. Journal of Personality, 69(6), 907-924. http://dx.doi.org/10.1111/1467-6494.696169

Verschueren, J. (1999). Understanding pragmatics. London: Arnold.

Wannaruk, A. (2008). Pragmatic transfer in Thai EFL refusals. RELC, 39(3), 318-337. http://dx.doi.org/10.1177/0033688208096844

Warnock, G. J., (1991). J. L. Austin. London: Routledge.

Widjaja, C. S. (1997). A study of date refusals: Taiwanese females vs. American females. University of Hawaii. Working Papers in ESL, 15(2), 1-43.

Williams, J. E., \& Best, D. L. (1982). Measuring sex stereotypes: A thirty-nation study. Beverly Hills, CA: Sage. Yule, G. (1996). The Study of Language. Cambridge: Cambridge University Press. 
Ghazanfari, M., Bonyadi, A., \& Malekzadeh, S. 